\title{
Medical trainees want benefit of doubt when reporting harassment
}

\author{
- Cite as: CMAJ 2018 March 26;190:E373-4. doi: 10.1503/cmaj.109-5579
}

Posted on cmajnews.com on Mar. 7, 2018.

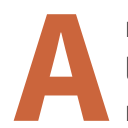
n online survey is shining a spotlight on pervasive sexual harassment in academia, including Canadian medical education. Medical trainees are urging schools to overhaul complaints processes that give benefit of the doubt to alleged predators at the expense of victims coming forward.

The anonymous, crowdsourced survey has amassed more than 2400 entries since December 2017, detailing a wide range of abuse, from lewd comments to groping to rape. The stories are unverified and stripped of most identifying details, but institutions and departments are named, including several Canadian medical schools.

Respondents describe how "powerful older men are gatekeepers to vulnerable younger women, use their power for sexual predation, and are then protected by other senior men and women," writes Karen Kelsky, a former anthropology professor at the University of Oregon and University of Illinois, who created the survey. "Women of color are doubly vulnerable and doubly bullied when they seek redress." In many cases, respondents didn't report abuse for fear of reprisal.

It's a story that's "disturbing and, unfortunately, all too common," says Dr. Melanie Bechard, president of Resident Doctors of Canada. In a 2014 review, the organization found that $45 \%-93 \%$ of residents experienced some form of harassment or intimidation during training, with 25\%-60\% experiencing sexual harassment.

Medical students report similar experiences. In a 2017 survey conducted by the Association of Faculties of Medicine of Canada, nearly $60 \%$ of final-year medical students said they were mistreated during training. Of those students, almost $90 \%$ said they were mistreated by faculty.

More than $80 \%$ never officially reported the mistreatment, and less than $36 \%$ of those who did complain were satisfied with the response.

Medical trainees are urging schools to believe reports of abuse are true unless proven otherwise. "The burden of proof should not be solely on the complainant," says Bechard. "Some may say it's intimi-

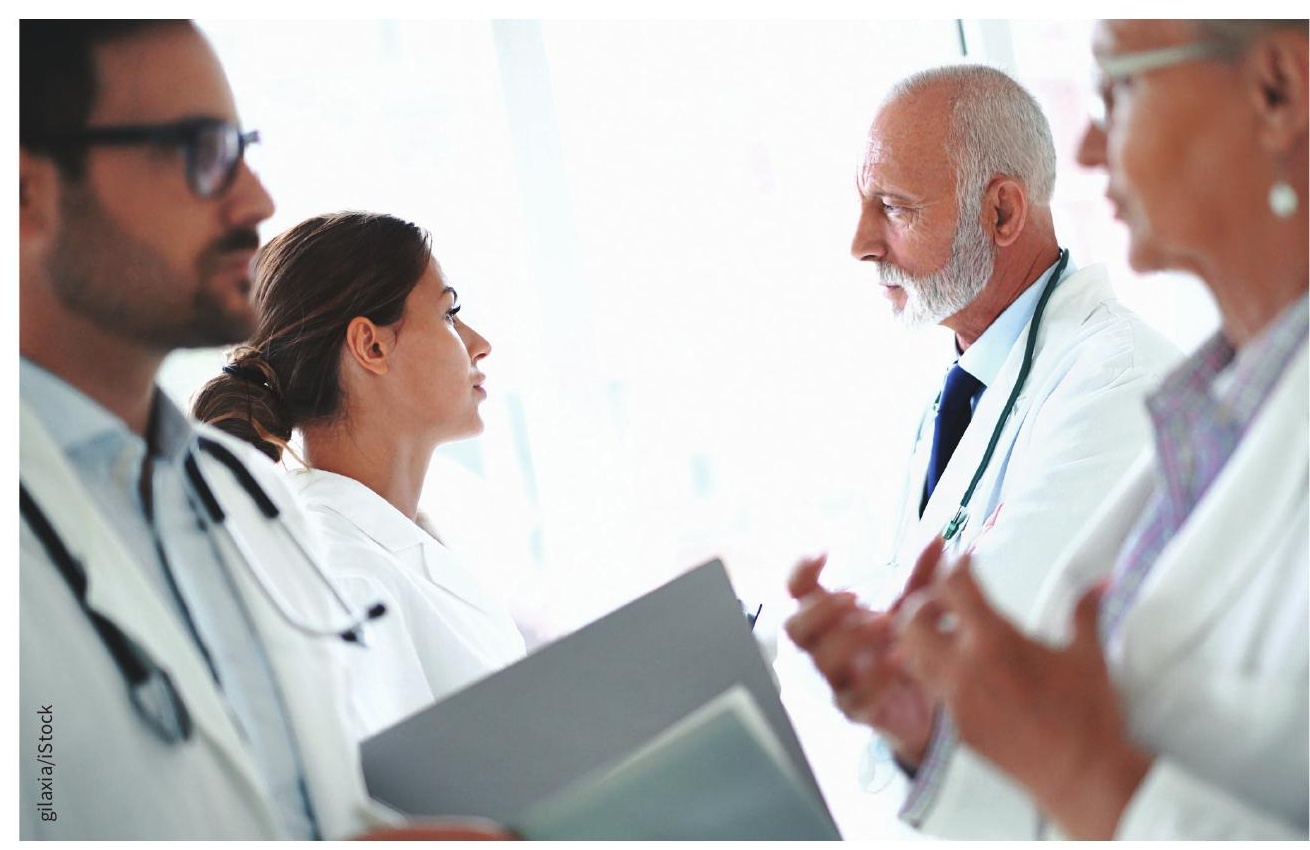

Power imbalances in medical training enable abuse and make it difficult to report, say trainee groups.

dating that one's entire personal [or] professional career could be devastated by claims of sexual harassment, but it's also intimidating to work in an environment where sexual harassment has no prospect for repercussions."

False accusations are uncommon and trainees have a lot to lose by reporting abuse, she adds. "Learners can see their future careers easily destroyed as a consequence of speaking out."
Stephanie Smith, vice-president of student affairs for the Canadian Federation of Medical Students, says the \#MeToo movement has been a reminder about the importance of believing and supporting victims. "We need to create a culture where it is safe for people to come forward and not be worried about feeling like they have to prove themselves." 
mous reporting option, says Dr. Sharon Whiting, interim vice-dean of faculty affairs. However, the school's response may be limited when complaints are anonymous. "We will investigate the incident, but we won't have any way of going back to that individual to say what was done," Whiting explains.

Other schools still require complainants to identify themselves. "Disciplinary investigations of a person subject to anonymous complaints would violate due process requirements," says Dr. David Eidelman, vice-principal of health affairs and dean of the faculty of medicine at McGill University. At McGill, complaints are "treated as confidential insofar as possible," he says, but getting students to trust the process remains a challenge.
In some cases, the pressure for information makes an already vulnerable situation more difficult. A resident at the Northern Ontario School of Medicine recently told the $C B C$ she was suspended after reporting sexual harassment by a faculty leader because she refused to disclose his identity unless the school appointed a third-party investigator. Dr. Ana Safavi said she wants to be certain there is a "transparent and fair process in place for everybody before I give any information." She told the CBC the school initially agreed to appoint an investigator, but "then they went back on that promise."

Bechard says third-party investigations may represent a viable option for balancing the rights of both the accuser and the accused. "The ability for objective review of allegations of sexual harassment would be helpful, while allowing for the anonymity of the complainant."

The potential fallout from reporting harassment outlives training, she adds. Abusive supervising physicians "often remain senior colleagues throughout a resident's medical career."

Smith notes that even anonymous complaints may be traced back if the abuse was targeted. Trainees known to have complained may also carry the label of troublemaker into their careers. "We have to support victims of sexual harassment, or any kind of harassment, from marginalization and retaliation," Smith says. "The school can only protect you so far."

Lauren Vogel, CMAJ 